Revista Española de Derecho Internacional Sección PRÁCTICA ESPAÑOLA DE DERECHO INTERNACIONAL Vol. 69/2, julio-diciembre 2017, Madrid, pp. 345-351 http://dx.doi.org/10.17103/redi.69.2.2017.3.02 (c) 2017 Asociación de Profesores de Derecho Internacional y Relaciones Internacionales ISSN: 0034-9380; E-ISSN: 2387-1253

\title{
FALTA DE JURISDICCIÓN DE LOS TRIBUNALES ESPAÑOLES PARA CONOCER DE DELITOS CONTRA EL MEDIO AMBIENTE (PESCA IUU) COMETIDOS POR ESPAÑOLES MEDIANTE BUQUES DE PABELLÓN EXTRANJERO EN ALTA MAR
}

(Sentencia del Tribunal Supremo, de 23 de diciembre de 2016, asunto Vidal Armadores)

\author{
Miguel García García-Revillo*
}

SUMARIO: 1. INTRODUCCIÓN.-2. ANTECEDENTES FÁCTICOS Y JURÍDICOS.-3. LA SENTENCIA DEL TRIBUNAL SUPREMO.-4. EL VOTO PARTICULAR.-5. CONSIDERACIONES FINALES.

\section{INTRODUCCIÓN}

1. Por Sentencia de 23 de diciembre de 2016, la Sala de lo Penal del Tribunal Supremo (TS), por cuatro votos contra uno, estimó el recurso de casación ${ }^{1}$ interpuesto por la defensa de los imputados contra el Auto de la Audiencia Nacional (AN), de 15 de junio de $2016^{2}$, donde este órgano, ratificando a su vez el Auto del Juzgado Central de Instrucción (JCI) núm. 3, de 9 de mayo de $2016^{3}$, afirmaba la jurisdicción de los tribunales españoles para conocer de un presunto delito contra el medio ambiente con arreglo a los arts. 335.1 y 4 y 336 del Código Penal (CP) cometido por nacionales españoles mediante buques de pabellón extranjero en alta mar. En dicha sentencia, el TS, además de casar y anular el auto recurrido, rechazando la jurisdicción de los tribunales españoles para conocer del caso, decidió el sobreseimiento libre, con el consiguiente archivo de las actuaciones y la puesta en libertad de los imputados.

\footnotetext{
* Profesor Titular de Derecho internacional público de la Universidad de Córdoba (miguelgarcia@ uco.es). Todas las páginas web de referencia han sido consultadas por última vez el 10 de mayo de 2017.

1 STS (Sala de lo Penal, Sección 1. ${ }^{\text {a }}$ ), de 23 de diciembre de 2016.

2 AAN (Sala de lo Penal, Sección 4. ${ }^{\text {) }}$, de 15 de junio de 2016 (Auto núm. 365/16, rollo de Apelación núm. 333/16).

3 Diligencias Previas núm. 114/15.
} 
2. Se trata de resoluciones judiciales de gran trascendencia mediática ${ }^{4} \mathrm{y}$ jurídica, tanto para el Derecho procesal interno español como para el Derecho internacional (DI), al plantearse por primera vez la cuestión de la jurisdicción de los tribunales españoles para conocer de delitos de pesca INDNR (ilegal, no declarada, no reglamentada) o IUU (por sus siglas en inglés, illegal, unreported and unregulated) cometidos por nacionales españoles mediante buques de pabellón extranjero en alta mar («aguas internacionales», en las palabras del TS).

\section{ANTECEDENTES FÁCTICOS Y JURÍDICOS}

3. En concreto, los hechos imputados habrían sido presuntamente cometidos por tres buques (Shongua, Yongding y Kunlun) de pabellón de Guinea Ecuatorial (cuestionado por el fiscal) y propiedad de armadores españoles (el conjunto empresarial Vidal Armadores, radicado en Galicia), sorprendidos por la Patrulla Naval de Nueva Zelanda, en enero de 2015, cuando se dedicaban a la pesca de la merluza austral en aguas antárticas sometidas a la Convención sobre la Conservación de los Recursos Vivos Marinos Antárticos (más conocida por sus siglas en inglés, CCAMLR), de 20 de mayo de 1980, de la que es parte España ${ }^{5}$, presuntamente sin licencia.

4. A raíz de estos hechos, la titular del JCI núm. 3 de la AN imputó a los nacionales españoles implicados un delito contra la protección de la fauna, previsto en los arts. 335.1 y 4 y 336 del CP, en concurso con otros delitos de pertenencia a grupo criminal, blanqueo de capitales y falsedad documental, derivados del primero. Por otra parte, accediendo a la petición del fiscal, la jueza instructora había acordado, en una resolución anterior, la prisión provisional de los imputados.

5. Cuestionada por la defensa la jurisdicción de los tribunales españoles, por entender que no se cumplían las condiciones exigidas por el art. 23 de la Ley Orgánica del Poder Judicial (LOPJ), concretamente en sus apartados 2 y 4, el JCI pronunció el 9 de mayo de 2016 un Auto por el que, desestimando las pretensiones de la defensa, afirmaba la jurisdicción de dichos tribunales para conocer del caso. En relación con el delito ambiental imputado, la instructora, en los Razonamientos Jurídicos del Auto, apoya la jurisdicción de los tribunales españoles en el citado art. 23 de la LOPJ, cuyos apartados $2^{6}$

\footnotetext{
4 Véase, por ejemplo, el diario El Mundo, de 14 de marzo de 2016 (http://www.elmundo.es/cronic a/2016/03/14/56e3f37546163f3e638b4588.html) y la Voz de Galicia, de 29 de diciembre de 2016 (http:// www.lavozdegalicia.es/noticia/maritima/2016/12/29/supremo-archiva-causa-contra-vidal-armadores-pesca-pirata-antartida/0003_201612G29P34991.htm).

5 BOE núm. 125, de 25 de mayo de 1985.

6 Según el art. 23.2 de la LOPJ: «También conocerá la jurisdicción española de los delitos que hayan sido cometidos fuera del territorio nacional, siempre que los criminalmente responsables fueren españoles o extranjeros que hubieran adquirido la nacionalidad española con posterioridad a la comisión del hecho y concurrieren los siguientes requisitos: a) Que el hecho sea punible en el lugar de ejecución, salvo que, en virtud de un Tratado internacional o de un acto normativo de una Organiza-
} 
y $3^{7}$ reproduce, conectándolo con los arts. II, III y XXI de la Convención CCAMLR antes referida. No analiza, en cambio, si los hechos eran punibles según la legislación del Estado del pabellón (Guinea Ecuatorial), afirmando, respecto a la nacionalidad de los buques implicados, que se trataba de pabellones de conveniencia. Más específico es, en cambio, el Auto, en cuanto al delito de integración en grupo criminal (art. 570 ter del CP), para cuyo conocimiento apoya la jurisdicción procesal española en el art. 23.4.j) de la LOPJ.

6. Por su parte, la Sala de lo Penal de la AN ratifica en su Auto de 15 de junio de 2016 la resolución de la jueza instructora, apelada por la defensa de los imputados, apoyando explícitamente la jurisdicción de los tribunales españoles, respecto al delito ambiental imputado, en el art. 23 de la LOPJ. A este respecto, en cuanto a la exigencia de que el hecho fuera punible en el lugar de ejecución, la AN, en los Fundamentos Jurídicos del Auto, afirma que la Convención CCAMLR «permite la extensión de la jurisdicción española para investigar y conocer los supuestos hechos con apariencia delictiva sujetos a escrutinio», citando al efecto los arts. II, XXI, XXII y XXIV de dicho tratado.

7. Por otro lado, la AN sostiene que «podemos acogernos a otros tres textos normativos para afirmar la jurisdicción española sobre los hechos que se investigan», citando al respecto el art. XIV de la Convención sobre el comercio internacional de especies amenazadas de flora y fauna silvestres ${ }^{8}$ (más conocida por sus siglas en inglés, CITES), de 3 de marzo de 1973, el art. 45 de la Constitución Española y el art. XXI de la Ley Orgánica 5/2010, de 22 de junio, de modificación del Código Penal ${ }^{9}$. Por lo demás, respecto a los delitos de constitución, financiación o integración en grupo u organización criminal, o los delitos cometidos en el seno de los mismos, la AN confirma la base legal de la jurisdicción de los tribunales españoles sobre el art. 23.4.j) de la LOPJ, como hiciera en su momento el JCI.

ción internacional de la que España sea parte, no resulte necesario dicho requisito, sin perjuicio de lo dispuesto en los apartados siguientes; b) Que el agraviado o el Ministerio Fiscal interpongan querella ante los Tribunales españoles; $c$ ) Que el delincuente no haya sido absuelto, indultado o penado en el extranjero, o, en este último caso, no haya cumplido la condena».

7 Según el art. 23.3 de la LOPJ: «Conocerá la jurisdicción española de los hechos cometidos por españoles o extranjeros fuera del territorio nacional cuando sean susceptibles de tipificarse, según la ley penal española, como alguno de los siguientes delitos:

a) De traición y contra la paz o la independencia del Estado.

b) Contra el titular de la Corona, su Consorte, su Sucesor o el Regente.

c) Rebelión y sedición.

d) Falsificación de la firma o estampilla reales, del sello del Estado, de las firmas de los Ministros y de los sellos públicos u oficiales.

e) Falsificación de moneda española y su expedición.

f) Cualquier otra falsificación que perjudique directamente al crédito o intereses del Estado, e introducción o expedición de lo falsificado.

g) Atentado contra autoridades o funcionarios públicos españoles.

h) Los perpetrados en el ejercicio de sus funciones por funcionarios públicos españoles residentes en el extranjero y los delitos contra la Administración Pública española.

i) Los relativos al control de cambios».

8 BOE núm. 181, de 30 de julio de 1986.

9 BOE núm. 152, de 23 de junio de 2010. 


\section{LA SENTENCIA DEL TRIBUNAL SUPREMO}

8. Frente a la posición tanto del JCI como de la Sala de lo Penal de la AN, la Sala de lo Penal del TS entiende, en su Sentencia de 23 de diciembre de 2016, que los juzgados y tribunales españoles no tienen jurisdicción para conocer de los delitos imputados. En opinión del TS, «ni la Convención para la Conservación de los Recursos Marinos Vivos del Antártico, ni los preceptos indicados de la LOPJ proporcionan las bases necesarias para la proclamación jurisdiccional» ${ }^{10}$.

9. Respecto a la aplicabilidad del art. 23.2 de la LOPJ, el TS sostiene que «la extensión de la jurisdicción española impone, por definición, la referencia que proporciona otro Estado que, conforme al primero de los presupuestos exigidos por el apartado $a$ ), ha de contar con una legislación penal que incrimine en su propio territorio la conducta imputada», de modo que la doble incriminación actúa "como condictio sine qua non para que el delito cometido fuera de España por un español o por un extranjero que hubiera adquirido la nacionalidad con posterioridad al hecho imputado, pueda ser investigado y enjuiciado por los tribunales españoles». De este modo, según el alto tribunal:

«de forma bien plástica podría decirse que el ciudadano español o el extranjero naturalizado que viajan más allá de nuestras fronteras, no llevan en su mochila un Código Penal con vocación de reprimir hechos cometidos allí donde tales conductas no han sido penalmente desvaloradas por el legislador del país de destino».

10. En el presente caso, concluye a este respecto el TS, «carece de sentido invocar la aplicación de este precepto, pues el hecho reputado delictivo fue cometido, según aclara la querella entablada por el Ministerio Público, en aguas internacionales», sin que esta circunstancia quede desvirtuada por el hecho de que esas aguas se encuentren en la zona de aplicación de la Convención CCAMLR ${ }^{11}$.

11. Por otra parte, extendiendo su análisis también al art. 23.3 de la LOPJ, entiende igualmente el TS que los hechos objeto de querella tampoco pueden ser encajados en ninguno de los tipos penales mencionados en ese apartado. En palabras de la Sala:

«Este precepto — clara expresión del principio real o de protección- no incorpora ninguno de los delitos imputados en la querella del Fiscal al repertorio de aquellas infracciones penales que pueden ser perseguidas por los tribunales españoles, sea cual fuere el lugar de comisión. Los delitos contra el medio ambiente por pesca ilegal (arts. 335 o 336 CP), falsedad documental (arts. 390 y 392 $\mathrm{CP}$ ) o integración en grupo u organización criminal (arts. 570 ter 1 y 570 quater 2 y $3 \mathrm{CP}$ ) no protegen, a juicio del legislador, un bien jurídico de valor singular para la comunidad nacional, hasta el punto de que resulte justificado romper las barreras impuestas por el principio de territorialidad».

10 STS (Sala de lo Penal, Sección $1 .^{\text {a) }}$, de 23 de diciembre de 2016, Fundamento 6. ${ }^{\circ}$

11 Ibid. 
12. Únicamente el delito de blanqueo de capitales, al establecer el art. 301.4 del CP su castigo aunque los actos de los que estos procedan «hubiesen sido cometidos, total o parcialmente, en el extranjero", permitiría su persecución extraterritorial. Sin embargo, en opinión del TS:

«mal puede hablarse de una actividad de blanqueo de capitales si las ganancias no provienen de un delito. La necesidad de un delito antecedente - una actividad delictiva dice textualmente el art. 301 del $\mathrm{CP}$ - opera como una exigencia del tipo, sin el cual el juicio de subsunción se desmorona» ${ }^{2}$.

13. De hecho, según la sentencia, asumiendo las alegaciones de la defensa, es en el art. 23.4.d) de la LOPJ ${ }^{13}$ donde se enumeran los delitos cometidos «en los espacios marinos» (sic), y en tal disposición «el listado [también] se olvida de los delitos por los que el Fiscal formula querella» ${ }^{14}$.

14. Por lo demás, en cuanto a la base ofrecida por la Convención CCAMLR, que el TS analiza en conexión con la "cláusula de cierre» establecida por el art. 23.4.p) de la LOPJ ${ }^{15}$, considera la sentencia que «la lectura de los principales preceptos de la Convención invocada en las resoluciones objeto de recurso [arts. III, XXI, XXII y XXIV] no revela un propósito de las partes contratantes de imponer la persecución penal obligatoria de las infracciones de pesca en la captura de austromerluza» ${ }^{16}$, a lo que añade que «el mismo tono programático, ajeno a toda nota de imperatividad, se aprecia en las previsiones del Reglamento 601/2004 CE del Consejo, de 22 de marzo, referido a las Medidas de control a actividades pesqueras en la zona de la Convención para la Conservación de Recursos Vivos Marinos Antárticos» ${ }^{17}$.

\section{EL VOTO PARTICULAR}

15. Frente a la posición mayoritaria, el Magistrado Del Moral García formuló un Voto Particular en el que expresó su discrepancia con la sentencia

12 STS (Sala de lo Penal, Sección 1. a), de 23 de diciembre de 2016, Fundamento $7 .^{\circ}$

13 Según esta disposición: «Igualmente, será competente la jurisdicción española para conocer de los hechos cometidos por españoles o extranjeros fuera del territorio nacional susceptibles de tipificarse, según la ley española, como alguno de los siguientes delitos cuando se cumplan las condiciones expresadas: d) Delitos de piratería, terrorismo, tráfico ilegal de drogas tóxicas, estupefacientes o sustancias psicotrópicas, trata de seres humanos, contra los derechos de los ciudadanos extranjeros y delitos contra la seguridad de la navegación marítima que se cometan en los espacios marinos, en los supuestos previstos en los tratados ratificados por España o en actos normativos de una Organización Internacional de la que España sea parte».

14 STS (Sala de lo Penal, Sección $1 .^{a}$ ), de 23 de diciembre de 2016, Fundamento 8. ${ }^{\circ}$

15 Según esta disposición: «Igualmente, será competente la jurisdicción española para conocer de los hechos cometidos por españoles o extranjeros fuera del territorio nacional susceptibles de tipificarse, según la ley española, como alguno de los siguientes delitos cuando se cumplan las condiciones expresadas: $p$ ) Cualquier otro delito cuya persecución se imponga con carácter obligatorio por un Tratado vigente para España o por otros actos normativos de una Organización Internacional de la que España sea miembro, en los supuestos y condiciones que se determine en los mismos».

16 STS (Sala de lo Penal, Sección 1. ${ }^{\text {) }}$ ), de 23 de diciembre de 2016, Fundamento $8 .^{\circ}$

17 Ibid., Fundamento $8 .^{\circ}$ in fine. Este reglamento se encuentra publicado en el DO L núm. 97, de 1 de abril de 2004. 
respecto a la recurribilidad en casación del auto impugnado y a la ausencia de jurisdicción de los tribunales españoles para conocer del caso.

16. Respecto a la recurribilidad en casación del Auto de la AN, el magistrado discrepante afirma que, sirviéndose de diversas "piruetas exegéticas», entre las que se incluye la de torcer «el axioma de que a la casación solo acceden las resoluciones definitivas, es decir, aquellas que ponen fin al proceso» salvo las excepciones muy contadas previstas en la ley, la sentencia «rompe las costuras del sistema legal de recursos frente a resoluciones interlocutorias». En palabras del magistrado:

«Se alumbra una decisión que, en lo que alcanzo a conocer, carece de cualquier precedente. Es no solo insólita, sino inédita: el Tribunal Supremo resolviendo una casación decreta ex novo (es decir, no por la vía de confirmar una resolución precedente) el sobreseimiento libre de unas diligencias previas en tramitación ${ }^{18}$.

17. Además de la discrepancia de índole procesal interna, el magistrado entiende, respecto a la cuestión jurisdiccional, que, en el estado en el que se encontraban las actuaciones (en fase de instrucción) no había base material ni jurídica suficiente para "concluir con rotundidad, como hace la sentencia mayoritaria, que la jurisdicción penal española carece de competencia para conocer de ninguno de los diversos hechos que se están investigando» ${ }^{19}$. A este respecto, en cuanto a la aplicación del principio de personalidad (art. 23.2 de la LOPJ) señala en su Voto Particular que, para entender si concurre o no el requisito de la doble incriminación, hay que estar «al pabellón del barco, Guinea Ecuatorial, que determina su nacionalidad y atrae la jurisdicción», subrayando, a este respecto, que, sobre la legislación de dicho país, "nada consta o nada se ha indagado», resultando "precipitado presumir que no existe norma penal alguna en tal nación que fuese aplicable» ${ }^{20}$.

18. Por otro lado, considera el magistrado discrepante «un argumento forzado y artificioso, que aletea tácitamente en el discurso de la mayoría, entender que, como en sí la actividad de pesca no se realiza en la embarcación, sino desde la embarcación, el hecho se habría producido en alta mar, es decir en tierra de nadie (o, mejor, para salvar la paradoja, en aguas de nadie)» ${ }^{21}$. A estos efectos, afirma:

«Esa exégesis, unida a una interpretación del principio de personalidad tan estricta como la manejada por la mayoría, lleva a consecuencias que se me antojan inasumibles. El principio de personalidad no permite perseguir una conducta que se ha realizado en un país cuya legislación no la castiga. Pero creo que no es correcto de ahí colegir que los espacios terrestres, marinos o espaciales, situados al margen de toda soberanía nacional, se convierten en pleno siglo XXI en ciudades sin ley, donde todo se puede hacer, salvo los delitos en los que rige el

18 STS (Sala de lo Penal, Sección 1. a), de 23 de diciembre de 2016, Voto Particular del Magistrado del Moral García, apartado II.

${ }_{19}$ Ibid., apartado III.

${ }^{20}$ Ibid.

${ }^{21}$ Ibid. 
principio de justicia universal y que conforman un listado amplio pero en cualquier caso limitado y con notables ausencias» ${ }^{22}$.

\section{CONSIDERACIONES FINALES}

19. La novedad del caso que comentamos, tanto por los aspectos de Derecho procesal interno español brevemente referidos como, en lo que concierne al Derecho internacional público, por tratarse de la primera vez en la que se planteaba la extensión de la jurisdicción de los tribunales españoles para conocer de un delito ambiental relativo a la pesca INDNR o IUU, cometido por nacionales españoles mediante buques de pabellón extranjero en alta mar, le dota de un alto interés jurídico, además del mediático ya referido.

20. Frente a la abundancia de asuntos en los que se ha extendido la jurisdicción de los tribunales españoles, en virtud del principio de justicia universal (art. 23.4 de la LOPJ), a delitos cometidos a bordo de buques de pabellón extranjero, por ejemplo, por tráfico de drogas ${ }^{23}$, el asunto que nos ocupa resulta difícilmente comparable a otros ya resueltos, por lo que es una incógnita lo que pueda suceder en el futuro con la persecución penal del tipo de conductas descrito. De mantenerse en futuras resoluciones la posición de la Sala de lo Penal del TS, en su Sentencia de 23 de diciembre de 2016, en el sentido de que, a los efectos del principio de personalidad (art. 23.2 de la LOPJ), el delito medioambiental imputado no es punible en el lugar de ejecución cuando es cometido por buques extranjeros en «aguas internacionales» (alta mar), con independencia de lo que establezca al respecto la legislación del Estado del pabellón de los buques desde los cuales se pesca, así como que tampoco resultan de aplicación a estos casos, para extender la jurisdicción de los tribunales españoles más allá de nuestro territorio, los principios de protección (art. 23.3 de la LOPJ) y jurisdicción universal (art. 23.4 de la LOPJ), al Estado español no le quedará otra opción que, o bien proceder a la modificación legislativa de la citada Ley Orgánica, para introducir expresamente las conductas descritas entre las cubiertas por los supuestos de los apartados 2, 3 o 4 de su art. 23, o bien renunciar a la persecución penal de este tipo de actos, asumiendo que nuestro país da por cumplidas sus obligaciones internacionales de lucha contra la pesca IUU únicamente mediante su represión por vía administrativa. Dadas las peculiaridades del caso, y la contundencia del Voto Particular emitido contra la mayoría, quizás sea aún pronto para sacar conclusiones de cierto alcance.

Palabras clave: pesca IUU, Derecho del Mar, delitos contra el medio ambiente, pabellón de conveniencia.

Keywords: IUU fishing, Law of the Sea, environmental crimes, flag of convenience.

22 Ibid

${ }_{23}$ Véanse, por ejemplo, entre las más recientes, STS (Sala de lo Penal, Pleno), de 24 de julio de 2014, STS (Sala de lo Penal), de 24 de julio de 2014 y STS (Sala de lo Penal), de 11 de diciembre de 2014, en los tres casos con imputados de nacionalidad extranjera. 